\title{
TRIBOLOGICAL STUDY OF NANO FLY ASH AS LUBRICATION OIL ADDITIVE FOR AISI 4140 STEEL FOR AUTOMOTIVE ENGINE APPLICATIONS
}

\author{
HARVINDER SINGH ${ }^{1}$, ANOOP KUMAR SINGH ${ }^{2}$, YOGESH KUMAR SINGLA ${ }^{3} \&$ \\ KASHIDAS CHATTOPADHYAY ${ }^{4}$ \\ ${ }^{1,2,3,4}$ Chitkara University Institute of Engineering and Technology, Chitkara University, Punjab, India \\ ${ }^{3}$ Research Associate, Department of Materials Science \& Engineering, Case Western Reserve University, USA
}

\begin{abstract}
The major concern of the researchers in automotive engine applications is to improve the tribological properties of a material, in order to increase the safety and save energy. Nano additives used with lubricants enhance the anti-wear properties of material when used in different proportions. A variety of nano additives has been used by many researchers to enhance the tribological properties of material, but many aspects of these nano additives and its potential still need to be explored. The effect of nano fly ash as an additive in lubricating oil on alloy steel used in automotive engine applications has to be studied. Fly ash nano particles (FNPS) $0.1 \%$ by weight were used as an additive in SAE 10 W-30 lubricant and wear behavior of AISI 4140, chromium molybdenum alloy steel was experimented using pin on disc laboratory set up. Three cases were taken under consideration. In Case I, the wear test was conducted in dry conditions. In Case II, SAE 10W-30 lubricant only was used and during Case III, Fly ash nano particles (FNPS) mixed in SAE 10W-30 lubricant were used while conducting the wear tests. The FNPS in SAE 10W-30 lubricant exhibited excellent wear characteristics by decreasing average wear loss and coefficient of friction (COF) remarkably. It was found that in Case II, the coefficient of friction and weight loss percentage decreased by $78 \%$ and $62 \%$ respectively in comparison to Case I. Where as in Case III, the coefficient of friction and weight loss percentage decreased by $79 \%$ and $32 \%$ respectively, when compared with Case II. The mechanism of reduced wear was studied using Scanning Electron Microscopy (SEM) and Energy Dispersive Spectroscopy (EDS).

KEYWORDS: Tribology; Lubricants; Nano Additives; Wear; Alloy Steel; Fly Ash Nano Particles
\end{abstract}

Received: Jun 09, 2020; Accepted: Jun 29, 2020; Published: Aug 01, 2020; Paper Id.: IJMPERDJUN2020564

\section{INTRODUCTION}

In steel industry, power plants, aerospace industry, automotive sector, oil industries, and many other manufacturing industrial applications, alloy steels are widely used. Few examples are gears, cams, forks slides, machinery parts, crankshafts, guide rod, hydraulic machinery, shafts,chain links, lathe spindles etc [1].

The friction plays an important role in the mechanical efficiency of the sliding components. Therefore the prime motive is to minimize the friction and wear to prevent the energy losses. Lubricating oil act to be quite beneficial in decreasing the friction in sliding components. The role of lubricants is to form an oil film between rubbing surfaces of the moving components thereby reducing wear. The thickness of film must be such that it is able to eliminating the contact in the moving components [2]. When the nano additives are mixe upto mild percentages in lubricanting oil,tribofilms get formed in between the surfaces. These nano particles help in generating nano ball bearing effect, therefore improving the wear charaterstics exceptionally. As per the literature available, the researchers who have studied the addition of nano metals [3] and nano-metal oxides, nano-metal sulfides [4], 
nano-carbonates [5], nano-borates[6], nano-carbon materials[7] and other organic nano particles in the oils, have reported tremendous reduction in friction and wear [9].

The physical and chemical properties of the nano additives effects the tribological behavior [10]. $\mathrm{SiO} 2$ nanoparticles with 0.05 to $0.5 \mathrm{wt} \%$ in liquid paraffin provides better wear properties than pure liquid parafin. Nano $\mathrm{SiO} 2$ mixed in paraffin liquid have exceptional load bearing tendency and better tribo results. Characterization techniquies like Scanning Electron Microscopy (SEM), Energy Dispersive Spectroscopy (EDS) and Atomic Force Microscopy (AFM) depicted that nano $\mathrm{SiO}_{2}$ formed tribofilm between the rubbing surfaces, there by reducing the wear and COF [11]. Nano $\mathrm{Al}_{2} \mathrm{O}_{3} / \mathrm{TiO}_{2}$ is used as an additives, which significanty reduced the COF and wear. A protective film was formed that converted sliding friction into rolling friction [12]. Even nano $\mathrm{Fe}_{2} \mathrm{O}_{3}$ and nano $\mathrm{CaO}$ in lubricants showed similar tribological results [13-14].

Similiarly, the effect of various nano additives in different proportions in lubricants has not been much explored and still needs deeper insight. Like wise effect of Fly Ash Nano Particles in lubricants have not been studied yet. Fly Ash Nano Particles consist of $\mathrm{SiO}_{2}$ and $\mathrm{Al}_{2} \mathrm{O}_{3}$ as major part of the composition and minor traces of $\mathrm{Fe}_{2} \mathrm{O}_{3}, \mathrm{CaO}$ and $\mathrm{TiO}_{2}$ [15]. Solving world wide disposing problem of fly ash, a waste product of thermal power plant is also a motivation behind choosing these nanoparticles for this study.

In this part of the experimental study, tribological behavior of an alloy steel, AISI 4140 in dry conditions, with lubricant SAE 10W-30 and with Fly Ash Nano Particles mixed in SAE 10W-30 was studied seperately as Case I, Case II and Case III respectively.

\section{EXPERIMENTATION}

Nano fly ash powder, Average Particle Size (APS) $<100 \mathrm{~nm}$, spherical in shape, was procured from Nanoshel-Intelligent Materials Pvt Ltd India. $10 \mathrm{~mm}$ rod of AISI 4140 was procured. Testing of the chemical composition was done using PMI (Positive material Indentification) technique. The chemical composition of the AISI 4140 used is given in the Table 1. AISI 4140 pin samples with round tip geometry, having diameter of $10 \mathrm{~mm}$ and length $40 \mathrm{~mm}$ were prepared. The pins were heat treated to $40 \mathrm{HRC}$ as per the standard procedure. After washing with acetone the pins were dried. Then these pins were weighed using digital balance AB-250D by Denver Instrument, having precision $0.01 \mathrm{mg}$.

Table 1: Chemical Composition of AISI 4140

\begin{tabular}{|c|c|}
\hline Elements & Percentage \% \\
\hline $\mathrm{C} \%$ & 0.382 \\
\hline $\mathrm{Si} \%$ & 0.233 \\
\hline $\mathrm{Mn} \%$ & 0.933 \\
\hline $\mathrm{S} \%$ & 0.005 \\
\hline $\mathrm{P} \%$ & 0.004 \\
\hline $\mathrm{Cr} \%$ & 0.902 \\
\hline $\mathrm{Mo} \%$ & 0.217 \\
\hline $\mathrm{Fe} \%$ & Rest \\
\hline
\end{tabular}

A pin on disc set up was used for conducting the tribological test as per the ASTM standard G99-17. Material of the disc was En 31 that was heat treated to 62 HRC. Lubricant SAE 10-W30 was used for conducting the wear test. 
Table 2: Parameters \& Conditions

\begin{tabular}{|c|c|c|c|c|}
\hline Case & Treatment & Load & Sliding Speed & Sliding Distance \\
\hline Case I & Without SAE 10W-30 \& FNPS & 15 & 1.5 & 1500 \\
\hline Case II & With SAE 10W-30 & 15 & 2 & 2500 \\
\hline Case III & SAE 10W-30 with FNPS & 15 & 2.5 & 3500 \\
\hline
\end{tabular}

Wear tests were conducted using the parameters and levels as per the Table 2. In Case I, the wear test was conducted without using any lubricant. Load on pin, sliding speed and sliding distance covered as $15 \mathrm{~N}, 1.5 \mathrm{~m} / \mathrm{s}$ and upto 1500 m respectively. In Case II, SAE 10W-30 lubricant oil was used to conduct the test at load, sliding speed and sliding distance 15 N, 2 m/s and upto 2500 m respectively. In Case III, SAE 10W-30 lubricant with Fly Ash Nano Particles was used to conduct the wear test at load, sliding speed, sliding distance $15 \mathrm{~N}, 2.5 \mathrm{~m} / \mathrm{s}$ and upto $3500 \mathrm{~m}$ respectively.

Frictional force was measured by using the load cell attached near the test pin holder and the data was recorded. Further the data was used to plot the graphs between coefficient of friction (COF) and sliding distance. After conducting the wear test samples pins were washed with acetone and were dried. These pins samples were weighed using the digital balance. SEM and EDS Spectroscopy was used to study the wear mechanisim in each category.

\section{RESULTS AND DISCUSSIONS}

The use of nano fly ash with lubricant resulted in significant reduction in wear of AISI 4140 workpiece material. The effect of presence of these nanoparticles has been tested and characterized using pin on disc wear test and SEM/EDS respectively. The shape of the fly ash wash spherical in nature as certified by the manufacturer

\subsection{Wear and Friction Behaviour of AISI 4140 Pins}

Fig. 1 shows the graph of coefficient of friction vs the sliding distance in Case I, with average COF calculated from the data as 0.5304. Fig. 2 shows the graph of COF vs sliding distance for Case II, with average COF as 0.1175. In the last case, Case III, the average COF resulted to 0.0249 and the graphs of COF vs sliding distance is shown in Fig. 3. Therefore it was found in Case II, there was a decrease in coefficient of friction upto $78 \%$ when compared to Case I. Where as in the Case III, the decrease in coefficient of friction was $79 \%$ when compared to Case II.

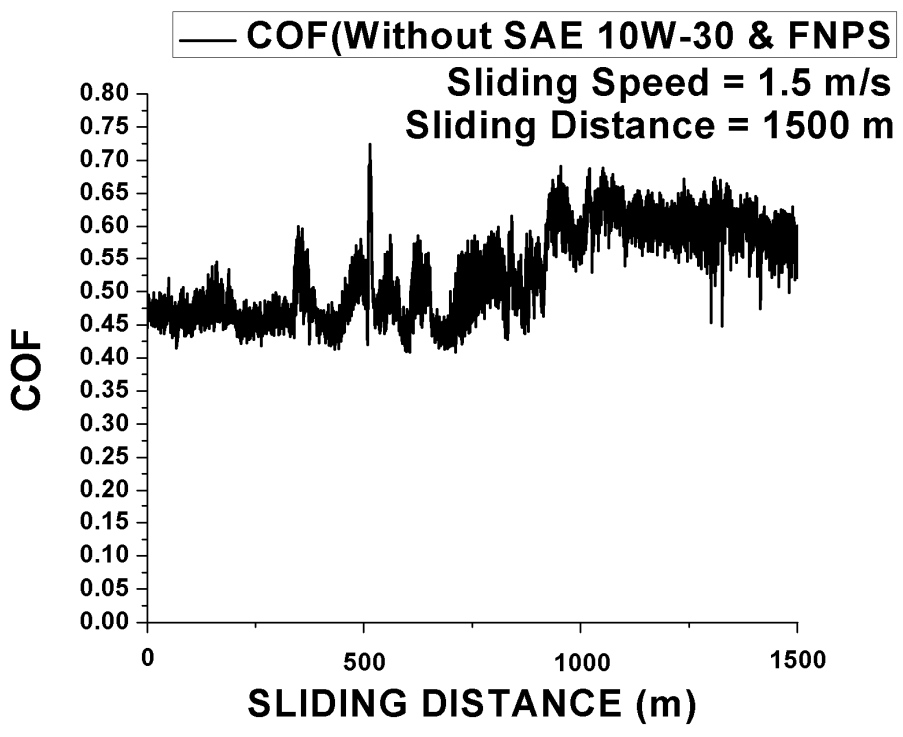

Figure 1: Coefficient of friction vs sliding distancefor Case I 




Figure 2: Coefficient of friction vs sliding distance for Case II

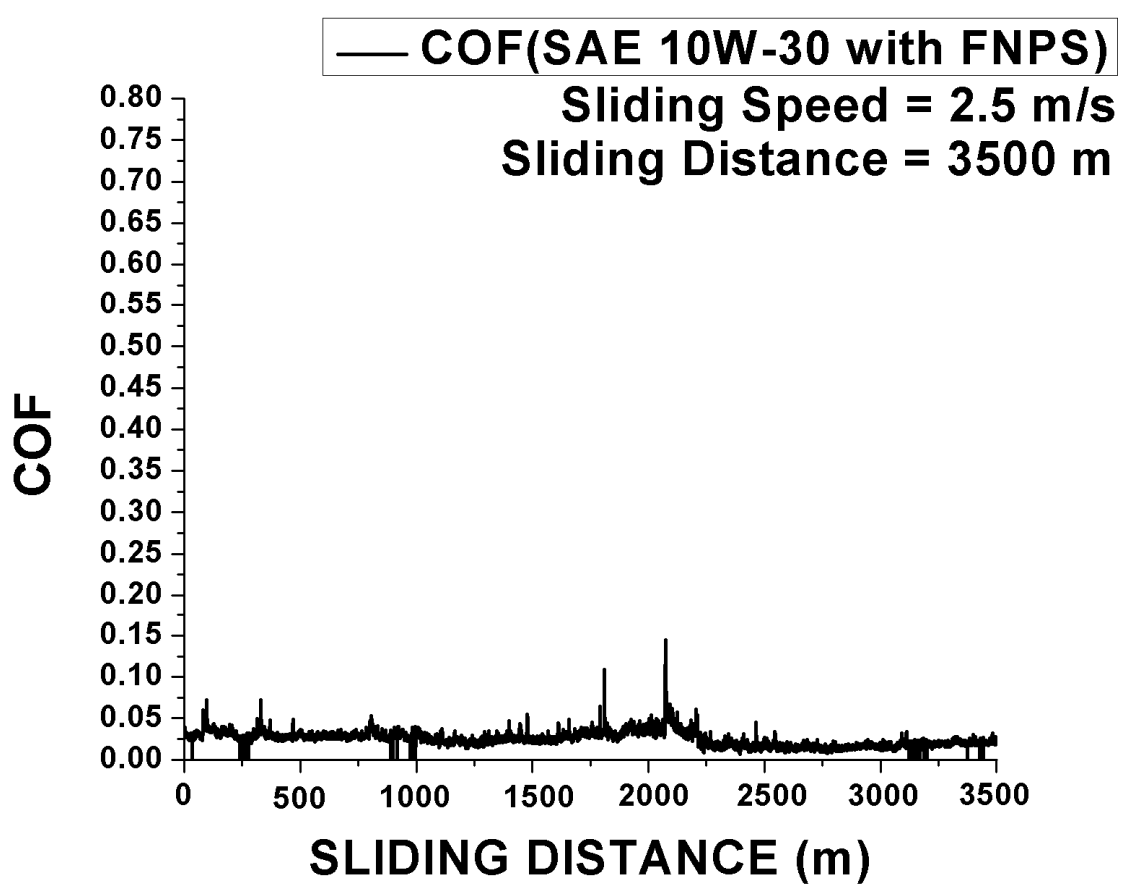

Figure 3: Coefficient of friction vs sliding distance for Case III 



Figure 4: (a) SEM image for Case I, (b) EDS results for Case I
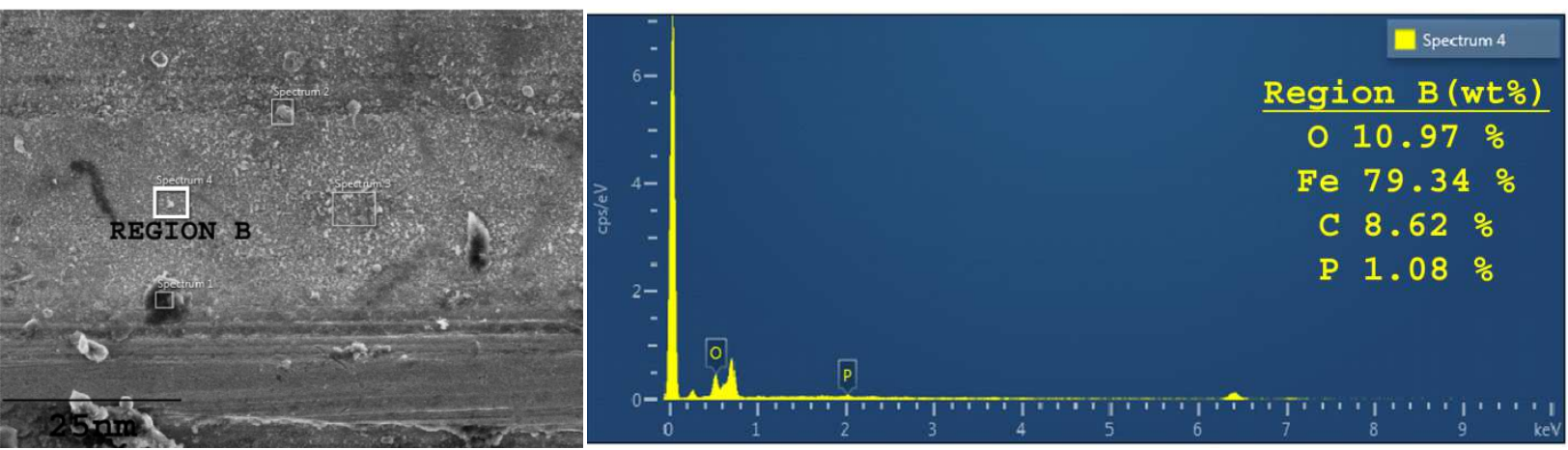

Figure 5: (a) SEM image for Case II, (b) EDS results for Case II
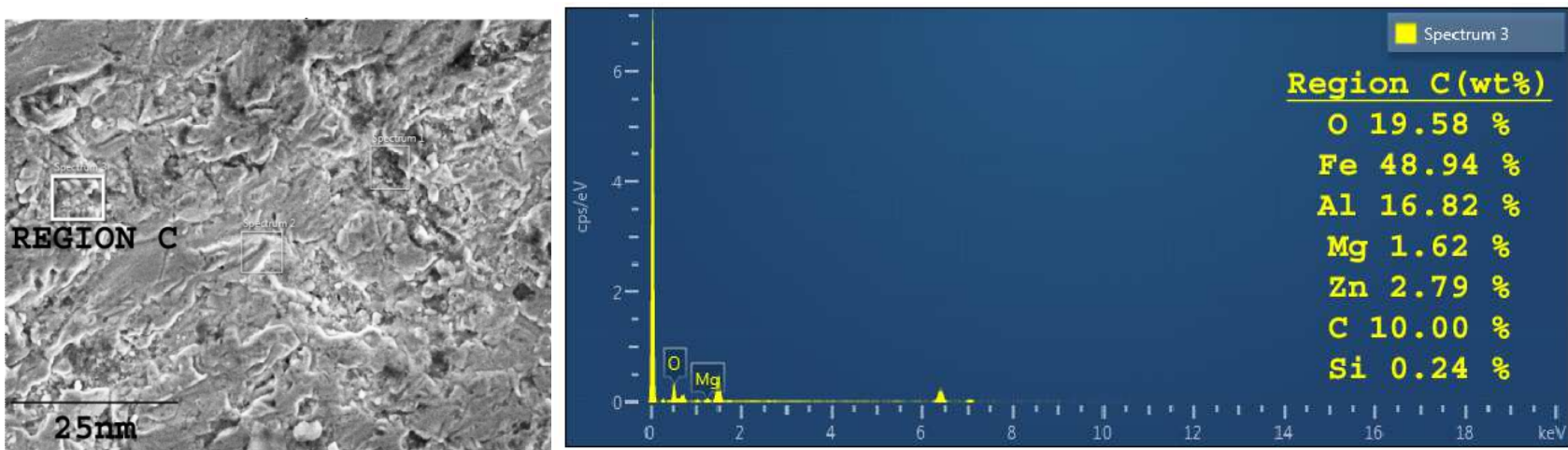

Figure 6: (a) SEM image for Case III, (b) EDS results for Case III

The COF vs sliding distance graph in Case III,reveals that COF decreases with respect to sliding distance. Fig. 3 shows that COF decreases after covering sliding distance of $2250 \mathrm{~m}$ and remains near about constant afterwards. At about $3250 \mathrm{~m}$ the COF also touches the zero line. Means at this point the nano particles totally acted as nano ball bearings and gave the rolling effect and zero coefficient of friction was ploted by the test rig. This was same as when spherical diamond nano particles were used in base oil, and COF decrease with sliding distance, was reported [16].

Wear loss by weight $(\mathrm{mg})$ in each category is given by Table 3. It was observed that wear loss percent by weight decreased upto $62 \%$ in Case II, as compared to Case I. In Case III, wear loss percent by weight decreased by 31 percent as compared to Case II.

\subsection{SEM/EDS and Wear Mechanism}

SEM and EDS results in Case I, Case II, Case III are shown in Fig. 4(a \& b), Fig. 5(a \& b) and Fig. 6(a \& b) respectively. The composition at selective regions is also reported on these figures. The traces of different elements were observed near about same in all the regions in each case, so best one was chosen and reported. SEM image in Fig. 4(a) shows that a litle 
scuffing has occurred in Case I. Fig. 5(a) shows the SEM image in Case II which clearly shows parallel grooves. In Case III slight scuffing has taken place as seen in Fig. 6(a).

EDS results of Case III when compared with Case I \& Case II, shows the traces of $\mathrm{Si}, \mathrm{Al}, \mathrm{Mg}, \mathrm{Zn}$ on wear scars due to the usage of Fly Ash Nano Particles. It can be reported that these elements are present in Fly Ash Nano Particles that got transferred and deposited in the scars due to friction. This is similar to tribological studies of other nano additives in lubricants. For example, EDS testing depicted the existence of Ti on the wear surfaces when, nano $\mathrm{TiO}_{2}$ was used as an additive in engine oil to study the wear properties of steel parts [17].

The nano particles under lubrication forms a tribofilm between the surfaces of the rubbing materials. The formation of tribofilm protects the metal contacts, therefore reducing COF \& wear. These particles embedded in worn pits breaks surface contact. Tribofilm bears load \& seprates the surfaces which results in wear drop. FNPS roll between the surfaces which results in mixed rolling and sliding friction. Therefore the coefficient of friction and wear reduces remarkably. The results also indicate the reduction in wear due to ball bearing effects of FNPS between the rubbing contacts. Similar results were reported when $\mathrm{ZnO}$ and $\mathrm{Al}_{2} \mathrm{O}_{3}$ were used as nanoadditives in lubricant[18]. It was reported that spherical nanoparticles acted as nano-sized bearings. Secondly nanoparticles resulted in a film formation between contacting region which resulted in reduction in coefficient of friction. This is also similar to, when nano-diamond particles were used in lube oil, Thin Film Lubrication Regime resulted in good antiwear and anti friction properties.

\section{CONCLUSIONS}

Fly Ash Nano Particles (FNPS) show excellent load carrying capacity and exceptional tribological properties when used on alloy steel in automotive engine applications. FNPS when used as an additive by $0.1 \%$ by wt to SAE $10 \mathrm{~W}-30$ in the wear test of AISI 4140, reduced the coefficient of friction upto $79 \%$ and wear loss percentage by weight upto $32 \%$ as compared to the case where only SAE $10 \mathrm{~W}-30$ lubricant. This is remarkable decrease in COF and wear loss, which suggests that the Fly Ash Nano Particles (FNPS) deduced from fly ash, which is the waste product in thermal power plants, can be beneficial to save energy and increase safety when mixed in lubricants.

SEM/EDS results depicted that thin tribofilm of Fly Ash Nano Particles (FNPS) was formed in between the contact surfaces of AISI 4140 pins and disc.These nano particles were able to bear the load as well as separate the surfaces to reduce COF \& wear. SAE 10W-30 lubricant resulted a drop in COF \& percent wear loss by weight(mg) upto $78 \%$ and $62 \%$ respectively, when compared to the dry conditions.

\section{REFERENCES}

1. Krelling, A., Souza, M., Costa, C. and Milan, J., "HVOF-sprayed Coating Over AISI 4140 Steel for Hard Chromium Replacement," Materials Research, 21,4,2018,1-10

2. Herdan, J., "Friction modifiers in engine and gear oils, " Lubrication Science," 12, 3, 2000, 265-276

3. BHAGYALAXMI, SATHYASHANKARA SHARMA, and ANUVAMSHI SHETTY. "QUENCH HARDENING AND MECHANICAL CHARACTERIZATION OF AISI 4140 STEEL."International Journal of Mechanical and Production Engineering Research and Development (IJMPERD) 9. 2, Apr 2019, 589-594

4. Liu, G., Li, X., Qin, B., Xing, D., Guo, Y. and Fan, R. (2004). Investigation of the Mending Effect and Mechanism of Copper Nano-Particles on a Tribologically Stressed Surface. Tribology Letters, 17(4), pp.961-966. 
5. Sharma, Sathyashankara, and Anuvamshi Shetty. "Quench hardening and mechanical characterization of AISI 4140 steel." International Journal of Mechanical and Production Engineering Research and Development 9.2 (2018): 589-594.

6. Chen, S., Liu, W. and Yu, L., "Preparation of DDP-coated PbS nanoparticles and investigation of the antiwear ability of the prepared nanoparticles as additive in liquid paraffin," Wear, 218, 2, 1998, 153-158.

7. Saravanan, A., et al. "Static analysis and weight reduction of aluminum casting alloy connecting rod using finite element method." Int J Mech Prod Eng Res Dev (IJMPERD) 8.3 (2018).

8. Rapoport, L., Feldman, Y., Homyonfer, M., Cohen, H., Sloan, J., Hutchison, J. and Tenne, R. (1999). Inorganic fullerene-like material as additives to lubricants: structure-function relationship. Wear, 225-229, 975-982

9. Hu, Z. and Dong, J., "Study on antiwear and reducing friction additive of nanometer titanium borate," Wear, 216,1, 1998, $87-91$.

10. KUSHWAHA, DIGVIJAY, et al. "EVALUATION AND OPTIMIZATION OF CUTTING PARAMETERS, FOR TURNING OF EN-8 STEEL: A TAGUCHI APPROACH. "International Journal of Mechanical Engineering (IJME) 6. 4, Jun - Jul 2017; 35-44

11. Huang, H., Tu, J., Gan, L. and Li, C., "An investigation on tribological properties of graphite nanosheets as oil additive," Wear, 261, 2, 2006, 140-144.

12. Rico, E., Minondo, I. and Cuervo, D. "The effectiveness of PTFE nanoparticle powder as an EP additive to mineral base oils," Wear, 262,11,2007, 1399-1406.

13. Zhang, B., Xu, B., Xu, Y., Gao, F., Shi, P. and Wu, Y., "Cu nanoparticles effect on the tribological properties of hydrosilicate powders as lubricant additive for steel-steel contacts, " Tribology International, 44, 7, 2011, 878-886.

14. Wu, Y., Tsui, W. and Liu, T., "Experimental analysis of tribological properties of lubricating oils with nanoparticle additives," Wear, 262,7, 2007, 819-825.

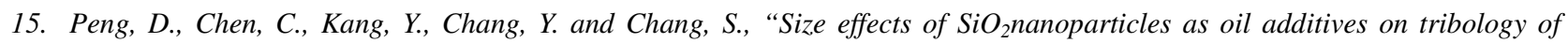
lubricant" Industrial Lubrication and Tribology, 62, 2, 2010, 111-120.

16. Luo, T., Wei, X., Zhao, H., Cai, G. and Zheng, X., "Tribology properties of Al2O3/TiO2 nanocomposites as lubricant additives," Ceramics International, 40, 7, 2014, 10103-10109.

17. Pardue, T., Acharya, B., Curtis, C. and Krim, J., "A Tribological Study of $\gamma$-Fe2O3 Nanoparticles in Aqueous Suspension," Tribology Letters, 66,4,2018

18. Aguilera-Camacho, L., Hernández-Navarro, C., Moreno, K., García-Miranda, J. and Arizmendi-Morquecho, A., “Improvement effects of $\mathrm{CaO}$ nanoparticles on tribological and microhardness properties of PMMA coating," Journal of Coatings Technology and Research, 12, 2, 2015, 347-355.

19. Kim, S., Hooton, R., Cho, T. and Lee, J., "Comparison of innovative nano fly ash with conventional fly ash and nano-silica," Canadian Journal of Civil Engineering, 41, 5, 2014, 396-402.

20. Shen, M., Luo, J. and Wen, S., “The Tribological Properties of Oils Added with Diamond Nano-Particles," Tribology Transactions 44, 3, 2001, 494-498.

21. Vijayaraj, M., Hait, S., Harinarain, A. and Ramakumar, S., "Tribochemical Transformation of Nano TiO ${ }_{2}$ to Ilmenite on the Surface of Wearing Steel Parts: Antiwear Action of Nano $\mathrm{TiO}_{2}$ as an Additive in Engine Oil," Tribology Transactions, 59, 3, 2016, 435-440. 
22. Gara, L. and Zou, Q., "Friction and Wear Characteristics of Water-Based $\mathrm{ZnO}$ and $\mathrm{Al}_{2} \mathrm{O}_{3}$ Nanofluids," Tribology Transactions, 55,3, 2012, 345-350. 